\title{
A MATERIALIDADE DAS NOVAS TECNOLOGIAS NO CONTEXTO DA RECEPÇÃO TRANSMIDIÁTICA
}

\author{
Guilherme Libardi ${ }^{1}$
}

Resumo: Este artigo tem como objetivo propor uma articulação entre a teoria da materialidade e os estudos de recepção considerando o contexto de transmidiação que se desenvolve no cenário social e tecnológico atual. Parte-se da premissa de que as múltiplas formas de produção e consumo convergentes complexificam as análises de recepção. Portanto, a partir de uma pesquisa bibliográfica apoiada em autores(as) que tratam da materialidade (GUMBRECHT, 2010; KITTLER, 1999; 2013) e da recepção transmidiática (LOPES, 2011; EVANS, 2011), compreendo que dialogar a teoria da materialidade da mídia com os estudos de recepção torna-se relevante a fim de explorarmos os limites e as subversões do uso dos meios por parte dos receptores, bem como compreender como estas práticas modulam os sentidos produzidos.

Palavras-chaves: Materialidade, recepção, transmídia.

Abstract: This paper aims at propose an articulation between the materiality theory and reception studies by considering the transmedia context that evolves at the current social and technological scenario. The premise that the multiple forms of convergent production and consumption complexifies reception analysis is assumed. Therefore, from a bibliographical research supported by authors that explore materiality (GUMBRECHT, 2010; KITTLER, 1999; 2013) and transmedia reception (LOPES, 2011; EVANS, 2011), I comprehend that dialogue the materiality media theory with reception studies become relevant in order to explore the limits and subversions of media use from receptors, as well as comprehend how these practices module the produced meanings.

Keywords: Materiality, reception, transmedia.

\section{Introdução}

O contexto do desenvolvimento e consumo das novas tecnologias ${ }^{2}$ vem sendo amplamente discutido no campo da comunicação a partir de diferentes correntes e eixos de investigação. Neste artigo, o objetivo é articular os pressupostos da teoria da materialidade alemã a partir de Gumbrecht (2010) e Kittler (1999; 2013) à emergente problemática da recepção transmidiática, apoiando-me em Lopes (2011) e Evans (2011). Desse modo, busco traçar alguns apontamentos demonstrando como e por que a teoria da materialidade encontra terreno fértil para ser incorporada no contexto dos estudos de recepção atuais.

Para pensarmos sobre a questão da materialidade na recepção, precisamos compreender que esta é parte intrínseca e constitutiva do processo de comunicação. A recepção diz respeito, em breves palavras, à produção de sentido elaborada pelo receptor ou

\footnotetext{
${ }^{1}$ Universidade Federal do Rio Grande do Sul.

${ }^{2}$ Me refiro, especificamente, aos gadgets e às plataformas digitais de redes sociais.
} 
receptora frente ao discurso e representação de um produto midiático específico, como uma telenovela, uma música ou um anúncio publicitário. Seria a etapa "final” do processo comunicacional, instante em que a mensagem é recebida pelo sujeito e interpretada a seu modo, de acordo com seu contexto, valores, ideologias e visões de mundo.

É verdade que os estudos de recepção privilegiam, desde o seu desenvolvimento na década de 1980 (JACKS; ESCOSTEGUY, 2005), um artefato específico para explorar este fenômeno: a televisão. A atualidade desta observação pode ser verificada em Meios $e$ audiências III, obra dedicada ao mapeamento das teses e dissertações brasileiras da área da comunicação que se preocupam com o tema da recepção e do consumo midiático (JACKS, 2017). Neste levantamento, que englobou o período entre 2010 e 2015, verificou-se que a televisão continua sendo o meio mais estudado. No entanto, o mapeamento constatou algo inédito: o surgimento de pesquisas que enfrentam a problemática da recepção em um cenário de convergência midiática (28 estudos ao total). A partir da leitura destes trabalhos, as autoras concluem que "diferentes meios podem estar em relação no cenário da convergência, o que traz a necessidade de diversas formas de análise de recepção" (PIENIZ; SILVA; MATOS, 2017, p.39). O típico caráter misto dos métodos e técnicas empregadas nos estudos de recepção (JENSEN; ROSENGREEN, 1990) é ainda mais ampliado, tornando-se necessário abraçar outros eixos teóricos e metodológicos.

Em resumo, nota-se o crescimento exponencial de trabalhos dedicados a explorar a relação entre sujeitos e novas tecnologias, preocupando-se principalmente com a descrição e análise dos usos e dos sentidos produzidos. Neste artigo, portanto, ensaio de que forma a teoria da materialidade pode ser incorporada aos estudos da recepção a fim de ampliar as suas possibilidades de análise. Esta parece ser uma questão importante de ser debatida levando em conta que, pela primeira vez, os estudos de recepção têm se deparado com uma vasta gama de novos aparatos informacionais e comunicacionais sendo utilizados pelos seus receptores, ampliando e complexificando a produção de sentidos frente aos discursos midiáticos. Não são mais somente consumidores de informação. Eles também a produzem e a fazem circular de forma a impactar o processo de produção que, até então, já estava institucionalizado. À esta nova configuração no fenômeno da recepção, nomeamos de "recepção transmidiática", conforme nomenclatura que vem sendo utilizada por estudiosas do campo, conforme é visto a seguir. 


\section{O emergente terreno da recepção transmidiática}

A recepção no âmbito das novas tecnologias abre espaço para repensarmos de que estudos de recepção estamos falando hoje. Desde 2010, algumas autoras têm se dedicado a explorar as novas dimensões da recepção no cenário de convergência, situando este fenômeno como "recepção transmidiática" (EVANS, 2011; LOPES, 2011). Esta nova "modalidade" de recepção está preocupada em tratar da complexidade que vem se delineando no processo de comunicação tendo em vista o desenvolvimento tecnológico e o seu acesso mais democratizado, focalizando a interação do sujeito com diferentes mídias ${ }^{3}$ consumindo a "mesma" mensagem. Utilizamos estes termos porque a transmidiação diz respeito à circulação de conteúdos em diferentes plataformas que tratem de um mesmo universo, sendo que em cada mídia há algo diferente a ser explorado sobre esta grande narrativa.

Em um contexto de pesquisas que se desenvolvem há décadas tendo a televisão como meio favorito, o consumo convergente surge gerando desconforto e dúvida, mas também podendo servir como catalisador de uma retomada de fôlego aos estudos de recepção, renovando-os e atualizando-os. Para isto, é necessário expandir o repertório no qual os estudos de recepção apoiaram-se até então, incorporar novas disciplinas e "dar as boasvindas" a autores de outras perspectivas - a princípio, nada extraordinário para um campo de estudos reconhecido como "altamente transdisciplinar". Isto não significa deixar de lado ideias que contribuíram para forjar o pensamento dos estudos de recepção em relação aos públicos e aos meios, como o de Martín-Barbero.

O impacto do desenvolvimento tecnológico é uma questão que vem sendo discutida pelo autor desde a década de 1980, com sua obra Dos meios às mediações. Naquela época, o autor já estava atento às mudanças que a tecnologia estava causando no mundo social e, em específico, nas estratégias de produção das grandes empresas de comunicação em nosso subcontinente. $\mathrm{O}$ autor situa sua discussão sobre o impacto tecnológico na relação entre cultura e comunicação a partir da mediação da tecnicidade. Para ele,

\footnotetext{
${ }^{3}$ A fim de refinamento de conceito, compreendemos mídia dentro da perspectiva dos estudos de recepção, que a define igualando seu conceito ao de meios de comunicação, ou seja, são os aparatos técnicos em que circulam produtos midiáticos (JACKS; ESCOSTEGUY, 2005).
} 


\begin{abstract}
A estratégica mediação da tecnicidade se delineia atualmente em um novo cenário, o da globalização [...]. Isso se dá não só no espaço das redes informáticas como também na conexão dos meios - televisão e telefone - com o computador, restabelecendo aceleradamente a relação dos discursos públicos e relatos (gêneros midiáticos) com os formatos industriais e os textos virtuais. As perguntas geradas pela tecnicidade indicam então o novo estatuto social da técnica [...] (MARTÍNBARBERO, 2001, p.19, grifos do autor).
\end{abstract}

Para o autor, a tecnicidade são as estratégias que se encontram mediando as lógicas do mercado, ou seja, as formas com que as empresas de comunicação se apropriam da tecnologia para inovar em seus produtos midiáticos, tendo como resultado tangível novos produtos e gêneros midiáticos. Ainda que ele sinalize para uma espécie de convergência (televisão telefone - computador), o autor não chega a pensar sobre a relação dos sujeitos consumidores com estas múltiplas formas de consumo simultâneas. A preocupação de Martín-Barbero recai com mais ênfase no polo da produção. Porém, atualmente, 30 anos depois da publicação de sua obra, com a pulverização das novas tecnologias nos lares e a partir da observação dos múltiplos usos possíveis destes gadgets, os estudos de recepção têm passado a se preocupar novamente com a questão das novas tecnologias, focalizando sua atenção nos usos e impactos destes no cotidiano dos receptores, levando adiante o pensamento de Martín-Barbero sobre o impacto social das novas tecnologias.

Lopes, ao tratar sobre a recepção transmidiática, afirma que um dos desafios é de que "certamente os textos dos novos meios colocam desafios específicos, pois eles são freqüentemente de natureza multimodal, hipertextual e efêmera" (2011, p.311). Notamos ainda que, além de uma preocupação com os novos textos produzidos nestes ciberespaços, é dada uma atenção especial em perceber de que forma este consumo digital interage e integrase ao que é recebido pelos produtos midiáticos que circulam na televisão - meio de comunicação considerado "tradicional" e tão caro aos estudos de recepção, conforme fora apontado. Evans expande o leque destes questionamentos, tentando pensar sobre o contexto de inserção destas novas tecnologias no cotidiano das audiências: "a pergunta então se torna, como estas tecnologias estão sendo integradas no cotidiano? Que escolhas as audiências estão fazendo e por quê?" (EVANS, 2011, p.65).

As discussões sobre recepção transmidiática se encontram em nível embrionário, principalmente no Brasil, surgindo mais questionamentos do que certezas. Algumas pesquisas têm sido realizadas na base da experimentação, através de softwares de análise de redes, e apoiadas em um repertório teórico sobre estudos de fãs (LOPES, 2011). É nesse cenário em 
que propomos a ampliação do repertório teórico-analítico para se pensar a recepção transmidiática. Diferentemente da televisão, cujos usos materiais não iam para muito além de ligar, aumentar ou baixar o volume e mudar de canal, as novas tecnologias possibilitam uma vasta gama de possibilidades de uso criativo de suas ferramentas, de sua própria materialidade enquanto aparato tecnológico. Evans é uma autora que se aproxima da discussão acerca da materialidade das novas tecnologias:

\footnotetext{
Uma televisão, ou VCR, ou DVD ou computador podem apenas fazer um certo número de coisas; existem coisas que eles são fisicamente e tecnologicamente incapazes de fazer. No entanto, ainda é difícil, se não impossível, prever se um indivíduo irá usar uma tecnologia de acordo com seus fins "pretendidos" e, se não, por quais fins eles podem usá-la (EVANS, 2011, p.65, tradução nossa).
}

A partir da possibilidade de múltiplos usos possíveis das novas tecnologias, abre-se espaço para deixar de lado, por um momento, a imaterialidade que cerca a curiosidade sobre “quais os sentidos produzidos pelo receptor", passando-nos a nos preocupar em "como o sentido é produzido por ele". Conforme é apontado por WINTHROP-YOUNG e WUTZ, “é necessário repensar a mídia com um novo e descompromissado grau de rigor científico, focando na lógica tecnológica intrínseca, nas ligações cambiantes entre corpo e mídia [...]" (1999, p. xiv). A teoria da materialidade é o eixo no qual localizamos esta discussão.

\section{Teoria da materialidade e estudos de recepção transmidiática: uma aproximação possível?}

Conforme foi desenvolvido até aqui, afirmo que existe uma lacuna presente nos estudos de recepção: o tratamento do sentido de maneira imaterial e deslocada do suporte concreto no qual é elaborado, sem levar em conta as possibilidades materiais dos usos e os condicionamentos que acabam sendo colocados pelo aparato técnico. Com o cenário de transmidiação, a potência da materialidade dos meios para compreender a recepção deve ser recolocada em pauta, uma vez que as novas tecnologias podem nos levar a escorregar para o mito da imaterialidade na forma de bits.

A teoria da materialidade é uma vertente de pesquisa que dá destaque à importância de se considerar os meios de comunicação, em seu nível material, para compreender de que forma a mensagem é produzida/inscrita e como esta configuração articula a produção do 
sentido. No cenário atual das tecnologias como redes sociais digitais, nuvem, streamings, algoritmos etc., a noção de que a mensagem circula de maneira imaterial é ainda mais sedutora. A questão da materialidade da comunicação busca resgatar a premissa de que por trás de todas estas tecnologias, existem múltiplas estruturas concretas que possibilitam, delimitam e condicionam a circulação destas mensagens: servidores, cabos, hardwares, baterias, etc. Gumbrecht resume a centralidade da teoria da materialidade da seguinte forma: "são todos os fenômenos e condições que contribuem para a produção de sentido, sem serem, eles mesmos, sentido" (2010, p.28). Compreendemos, portanto, que estruturas inorgânicas não apenas modulam as mensagens, como também agem sobre o corpo orgânico - nós, humanos - locus no qual a recepção acontece. A teoria da materialidade, portanto, adota a perspectiva de que a materialidade da comunicação, os meios em si, afetam o sentido produzido das mensagens que transportam.

Ao estender sua crítica sobre a desmaterialização que habita os estudos sobre produção de sentido - que aqui situamos como estudos de recepção -, Gumbrecht constata que os aportes conceituais utilizados para compreender as interpretações dos sujeitos "continuam a pressupor que a comunicação é predominantemente acerca do sentido, acerca de algo espiritual que é transportado e precisa ser identificado 'para além das superfícies puramente materiais' do material” (2010, p.37). A proposta, portanto, é superar uma suposta dimensão metafísica da recepção, considerando as materialidades que envolvem o fenômeno.

Entendemos, então, que a teoria da materialidade pressupõe que o sentido só é produzido mediante uma presença em relação ao nosso corpo. Gumbrecht assinala que a “presença refere-se, em primeiro lugar, às coisas [re extensae] que, estando à nossa frente, ocupam espaço, são tangíveis aos nossos corpos [...]” (2010, p.9). Ou seja, estamos falando da coisa material, daquilo que, por si só, não carrega nenhum significado a priori; mas que ao ser colocado em relação a nós, é capaz de produzir sentido. No cenário das novas tecnologias, embora esta pressuposição se torne nebulosa, não deve ser ignorada. A pesquisa empírica com sujeitos, em um cenário de novas tecnologias e de transmidiação, deve conscientizar-se das condições materiais que interpelam os receptores no momento da produção de sentido frente aos discursos que emanam destas múltiplas plataformas - desde as mais tradicionais, até as mais contemporâneas. Conforme colocado por Evans (2011), em um contexto de múltiplos aparatos midiáticos, torna-se complexo prever que forma os sujeitos farão uso de cada tecnologia. Martín-Barbero (2001) também chama atenção a este aspecto, considerando a 
espontaneidade e criatividade das lógicas de usos por parte dos receptores, quase sempre plurais e imprevisíveis. Portanto, antes de compreender o sentido, torna-se relevante entender o meio. Não apenas na relação interativa de receptor e aparato, mas nas condições em que o meio é constituído, fabricado e como as mensagens são veiculadas nele.

Além de Gumbrecht, Kittler também contribui para pensar a teoria da materialidade e sua centralidade para a compreensão dos sentidos. Na introdução de Gramophone, film, typewriter, os tradutores responsáveis pela versão de língua inglesa da obra realizaram um claro resumo das principais ideias do autor, colocando que "a questão sobre como as pessoas operam a mídia deve, então, ser complementada pelo igualmente importante questionamento sobre como a mídia opera as pessoas" (WINTHROP-YOUNG; WUTZ, 1999, p.xxii, tradução minha). Novamente, a proposta não é ignorar a produção do sentido e os usos das mídias ${ }^{4}$, mas sim incorporar a questão da materialidade para compreender que "o simbólico abrange signos linguísticos em sua materialidade e tecnicidade" (KITTLER, 1999, p.15, tradução minha). Fazendo referência a Lacan, o autor ainda expõe, nas palavras do psicanalista, que o mundo do simbólico é o mundo das máquinas. Compreendendo como o meio funciona, compreenderemos de que forma os receptores desenvolvem sentidos que podem ser bastante concretos, ou simbólicos, habitando o nível do imaginário ou do inconsciente.

Esta questão torna-se relevante ao nos darmos conta das sensações que nos ocorrem ao experienciarmos as diferenças entre ler um livro físico e digital; ver um filme no cinema e baixa-lo e assisti-lo na tela da televisão, em casa; ler notícias em um jornal físico e no aplicativo de um veículo de comunicação instalado em nosso smartphone. É isto que a teoria da materialidade busca complexificar a fim de alimentar a compreensão da produção de sentidos. Os estudos de recepção, portanto, podem encontrar um terreno fértil neste campo de estudos, uma vez que, conforme apontado pelos teóricos alemães, o aparato tem capacidade de modular a nossa percepção da mensagem.

A proposta, portanto, nos termos de Kittler, é a prática da "descida do software para o hardware - do mais alto ao mais baixo nível de observação [...]” (2013, p.223, grifo meu, tradução minha). O que isso significa é que devemos ir além da "superfície" do meio, compreendendo o seu modo de operação, estendendo este entendimento às suas implicações na recepção.

\footnotetext{
${ }^{4}$ Diferentemente da perspectiva dos estudos de recepção, Kittler é mais abrangente, e considera mídia como todo o artefato que calcula, armazena e transmite dados: "Mídia inclui coisas antigas como livros, coisas familiares como cidades, e coisas novas como computadores" (1999, p.143, tradução minha).
} 


\section{Considerações finais}

Busquei, neste artigo, fazer dialogarem os estudos de recepção num contexto de transmidiação e a teoria da materialidade alemã. Para tanto, realizei um resgate sobre as principais preocupações dos estudos de recepção e delineei os novos desafios que devem ser enfrentados no atual contexto de produção e consumo digitais transmidiáticos. Verifiquei a centralidade que é fornecida à produção de sentidos por parte do receptor e de um certo esquecimento no que diz respeito à preocupação com o suporte material no qual a recepção ocorre. Com o advento de estratégias transmidiáticas, este "esquecimento" torna-se um problema ainda maior, uma vez que as novas tecnologias, cada uma a seu modo, funciona de forma diferente e complexa, podendo moldar a interpretação das mensagens de diversas maneiras. Ao mesmo tempo, a complexidade destes gadgets fornecem ainda maiores possibilidades de usos por parte dos receptores que os utilizam e que neles consomem. Conforme discorri ao longo deste texto, é necessário que consideremos materialidade mesmo, e principalmente, daquilo que se invisibiliza na forma de bits. Afinal, a materialização destas sequências de 01s necessitam de uma plataforma tangível para se fazerem existir de forma a "produzir presença" (GUMBRECHT, 2010).

A teoria da materialidade, portanto, fornece um chão para que os estudos de recepção possam repensar seus conceitos-chaves e alimentarem-se de uma perspectiva capaz de fornecer uma base para pensar os meios. Parece necessário, portanto, dar "um passo para trás" no entendimento do processo de recepção e dedicar tempo e rigor para compreender os aspectos materiais da comunicação, com foco nas novas tecnologias, que vêm articulando a produção de sentidos de modo tão plural. Dessa forma, conseguiremos visualizar até que ponto o receptor estaria "engessado" nos limites do meio de comunicação ou, por que não, subvertendo e indo além de sua "utilidade pretendida" (EVANS, 2011).

Por fim, considero que em um contexto de recepção transmidiática, a questão da materialidade torna-se relevante tendo em vista a heterogeneidade de meios que fazem parte do cotidiano dos receptores. Os sentidos produzidos em cada meio, ainda que façam parte de uma mesma narrativa, serão outros. Este é o objetivo de uma estratégia transmidiática. Compreendendo a materialidade destes aparatos, alcançaremos outro nível de descrição dos usos sociais realizados pelos sujeitos. 


\section{Referências}

EVANS, Elizabeth. Transmedia television: audiences, new media and daily life. New York: Routledge, 2011.

GUMBRECHT, Hans Ulrich. Produção de presença: o que o sentido não consegue transmitir. Rio de Janeiro: Contraponto. 2010.

JACKS, Nilda; ESCOSTEGUY, Ana Carolina. Comunicação e recepção. São Paulo: Hacker Editores, 2005.

JACKS, Nilda (org.). Meios e audiências III. Porto Alegre: Sulina, 2017.

JENSEN, Klaus Bruhn; ROSENGREN, Karl Erik. 5 traditions in search of the audience. In: European Journal of Communication, 5:207, 1990.

KITTLER, Friedrich A. Gramophone, Film, Typewriter. Standford: Standford University Press. 1999.

The truth of the technological world. Standford: Standford University Press. 2013.

LOPES, Maria Immacolata Vassalo de. A recepção transmidiática da ficção televisiva: novas questões de pesquisa. In: Estudos de TV Brasil-Portugal. 2011. Disponível em: <https://doi.org/10.13140/2.1.1339.8085 >. Acessado em: 13 jan. 2017.

MARTÍN-BARBERO, Jesús. Dos meios às mediações: comunicação, cultura e hegemonia. Rio de Janeiro: Editora UFRJ, 2001.

PIENIZ; Mônica Bertholdo; SILVA, Roger Teodoro da; MATOS, Ludimila Santos. Sujeitos em trânsito na internet. In: JACKS, Nilda (org.). Meios e audiências III. Porto Alegre: Sulina, 2017.

WINTHROP-YOUNG; Geoffrey; WUTZ, Michael. Translators' introduction: Friedrich Kittler and Media Discourse Analysis. In: KITTLER, Friedrich A. Gramophone, Film, Typewriter. Standford: Standford University Press. 1999. 